\title{
IgG Levels in Mother-Father-Cord Trios ${ }^{1}$
}

\section{Evidence for a Large Reduction of Maternal IgG at Birth}

\author{
Robert C. Williams ${ }^{2}$ and Henry Gershowitz \\ Department of Human Genetics, The University of Michigan Medical School, Ann Arbor, Mich.
}

\begin{abstract}
Cord plasmas have a higher concentration of IgG than do the mothers, although autologous, fetal immunoglobulin $G$ is only a small fraction of the neonate's complement. Maternal IgG levels are significantly lower than the nonpregnant adult female, a loss of about one third, which cannot be explained completely by maternal immunization of the fetus.
\end{abstract}

Conflicting data have been published concerning the relative amounts of maternal and fetal IgG in the neonate $[1,4,5,8]$. The purpose of the present study was to determine whether cord plasmas from full-term infants do have higher concentrations of immunoglobulin $G$ than do their mothers and whether the IgG is of maternal or fetal origin.

\section{Materials and Methods}

The IgG levels of $\mathbf{4 2}$ mother-father-cord plasmas (actually 43 cord plasmas were tested because of the birth of twins) were measured by commercial single radial immunodiffusion plates (Quantiplate, Kallestad). The families were drawn from

1 This work was supported by DOE Contract EY-76-C-02-2828.

2 Recipient of a Postdoctoral Fellowship from NIH Grant 1T32-GM-07123 awarded to the University of Michigan. the University of Michigan Women's Hospital and are part of a mutation study by the Department of Human Genetics (Department of Energy contract E(11-1)-2828). Umbilical cord samples were expressed into $2 \mathrm{ml}$ of acid citrate dextrose (ACD). Mother and father blood samples were also drawn into $2 \mathrm{ml}$ of $\mathrm{ACD}$, all plasma being frozen at $-30^{\circ} \mathrm{C}$ until testing.

The plasma were centrifuged at $2,500 \mathrm{rpm}$ for $30 \mathrm{~min}$ at room temperature before being tested in duplicate, with duplicate standards on each plate. The three plates from each kit were used on the same day to minimize variations in time and temperature. Each plate was incubated for $18 \pm 0.5 \mathrm{~h}$ at room temperature and the diameters of the precipitin rings measured on a calibrating viewer (Transidyne General). The six values for each standard, for each set of three plates, were averaged and the mean values plotted on semi-logarithmic paper to construct a standard curve from which the IgG concentrations in $\mathrm{mg} / \mathrm{dl}$ were read. Plasma having IgG levels below the sensitivity of the standard immunodiffusion kits were tested again on low level plates (Kallestad). Hematocrits and total blood volumes of all samples were noted and the measured IgG concentrations adjusted to 
correct for the dilution effect of $2 \mathrm{ml}$ of $\mathrm{ACD}$. Hemagglutination inhibition tests for Gm allotype, immunodiffusion, and immunoelectrophoresis were done by standard techniques [9].

\section{Results}

In all but four families the concentration of $\mathrm{IgG}$ in $\mathrm{mg} / \mathrm{dl}$ was greater in the cord than in the maternal plasma. The means, standard deviations, and distributions of mother, father, and cord IgG are presented in figure 1. Cord plasma had the highest mean concentration, $1,228 \mathrm{mg} / \mathrm{dl}$, while mothers' concentration was the lowest, 755 $\mathrm{mg} / \mathrm{dl}$. Fathers had an intermediate value of $1,100 \mathrm{mg} / \mathrm{dl}$. To assess the extent of the reduction in maternal $\mathrm{IgG}$, the distributions of the differences between the cords and their mothers (cord minus mother) and between cords and fathers (cord minus father) were compared. Since adult male and adult, nonpregnant female IgG levels are approximately equal $[6,7]$, this comparison tests the null hypothesis that pregnant full-term women and nonpregnant females have equal mean IgG concentrations. The histograms of the differences, cord minus mother and cord minus father, fit the expectations from the normal, theoretical histogram. Therefore the equality of the means of the distributions was tested with a $t$ test. The null hypothesis of equality was rejected at the 0.001 level of significance.

At a standard plasma dilution of 1:30 (standard in H.G.'s laboratory for several years), Gm phenotypes of mother-cord pairs were identical in all but one family in which

Fig. 1. Histograms of IgG concentration, $\mathrm{mg} /$ dl: mothers, $n=42$, mean $=754, S D= \pm 267$; fathers, $\mathrm{n}=42$, mean $=1,099, \mathrm{SD}= \pm 288$; cords, $\mathrm{n}=43$ (one set of twins), mean $=1,228, S D= \pm 422$.
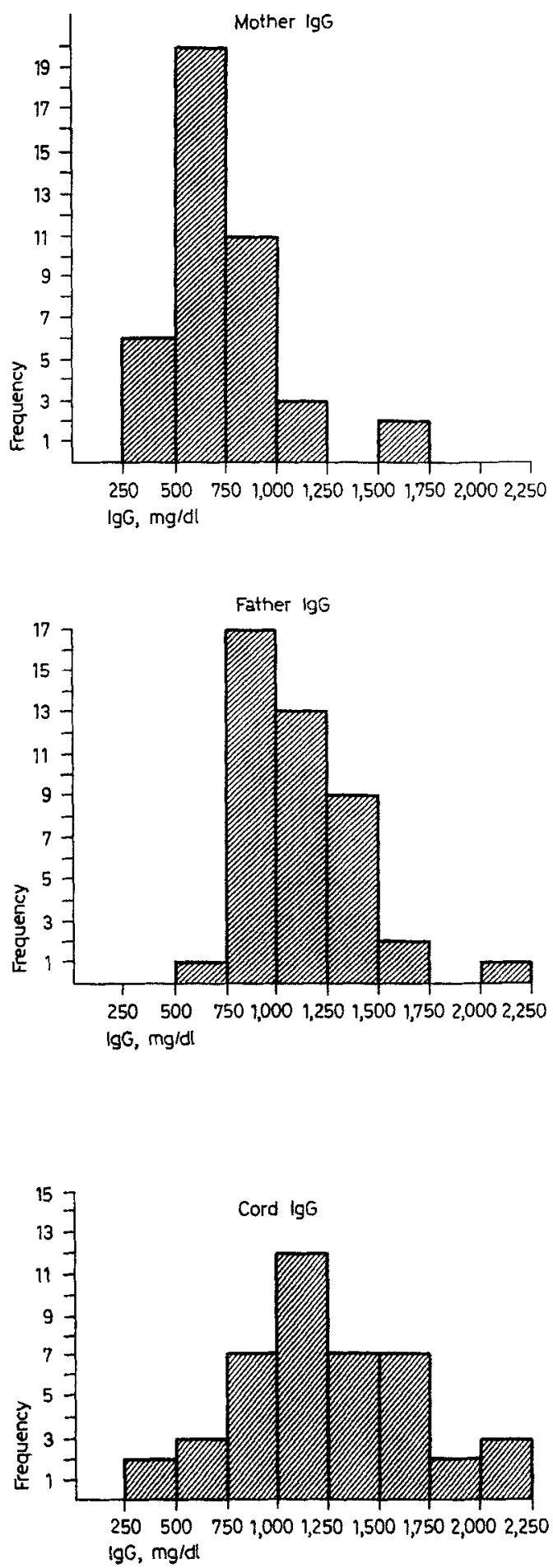
paternal antigen, fetal IgG, was detected. In each of the four families in which the maternal level of IgG was greater than the cord, the cord plasma were tested for the presence of $a_{1}$-fetoprotein by immunodiffusion against anti- $\alpha_{1}$-fetoprotein (rabbit, Behringwerke). All four cord samples had detectable fetoprotein while the four sets of parents had no detectable levels of the fetal peptide, confirming their proper identification.

\section{Discussion}

The observations that there is a one and a half to twofold greater concentration of IgG in the cord as compared to the mother and that mother-cord $\mathrm{Gm}$ phenotypes are identical at plasma dilutions of 1:30 contain both novel and accepted patterns for motherfetal immunization. First, this study confirms previous work that has reported a higher concentration of IgG in the cord plasma at birth [3]. Second, these data demonstrate that autologous IgG constitutes only a small fraction of the infant's total amount when he is born. What is most surprising, however, is the third conclusion from the data, that women, immediately after they give birth, have a very low level of immunoglobulin G. Using fathers' distribution of $\mathrm{IgG}$ as an adult standard, it can readily be seen that mothers are depleting their own pool of IgG and transferring it to the fetus. This reduction could not be due merely to the maintenance of an equilibrium across the placental membrane, as has been suggested [5], but would seem to be the result of an active mechanism by which the concentration gradient is maintained; either the mother pumps her IgG across the membrane and/or the fetus selectively retains maternal IgG after it has crossed the placental barrier. Evidence for the latter mechanism comes from the active transport of fetal IgG in the opposite direction against the large concentration gradient between mother and fetus [10]. The ability of the fetus to transfer its own IgG suggests an active, selective, retention of maternal immunoglobulin.

The depletion of maternal IgG cannot, however, be completely explained by either fetal retention or maternal transport. If $a b-$ solute amounts of immunoglobulin $\mathrm{G}$ are computed, instead of concentration units, and the number of grams of IgG that are depleted from the mother compared to the number of grams gained by the neonate, then it is easily shown that the mother loses approximately six times as much IgG as is found in the neonate's plasma. In order to compute the estimate it is assumed that the mean maternal volume is 4.5 liters and that of the neonate $270 \mathrm{ml}$. Hematocrit and IgG concentration have been measured for each mother and neonate and are incorporated into the estimate for total $\mathrm{IgG}$ in grams. Mean maternal IgG at the time of birth is $20.43 \mathrm{~g}$, that of the cord $1.59 \mathrm{~g}$. Using the adult mean of $1,100 \mathrm{mg} / \mathrm{dl}$, the nonpregnant adult woman would have, on the average, $30.05 \mathrm{~g}$ of IgG. Therefore pregnant, fullterm women have $9.62 \mathrm{~g}$ less than average which is approximately six times the amount of immunoglobulin $\mathrm{G}$ in the neonate $(1.59 \mathrm{~g})$.

Why there is this large discrepancy between the amount lost by the mother and that gained by the child is not known, but it suggests that there is a lower threshold for maternal IgG levels. The mother loses large amounts of $\mathrm{G}$ immunoglobulin, about one third her adult supply; the fetus is passively immunized by a portion but most of the loss cannot be explained. Yet there is a sharp 
threshold, about $600 \mathrm{mg} / \mathrm{dl}$, about which maternal IgG values cluster, as can be seen from the shape of the mothers' histogram. It is highly restricted, kurtotic, and skewed to the right. The null hypothesis of normality can be rejected at the 0.001 level of significance. In contrast, the distribution of fathers' IgG is less restricted whereas the cord IgG histogram closely approximates that generated from a theoretical normal distribution.

\section{References}

1 Allansmith, M.; McClellan, B. H.; Butterworth, M., and Maloney, J.R.: The development of immunoglobulin levels in man. J. Pediat. 72: 276-290 (1968).

2 Daveau, M.; Rivat, L.; Ropartz, C., and Fessard, C.: Gm and Inv allotypes in premature infants. Biomedicine 23: 23-27 (1975).

3 Gitlin, D.; Kumate, J.; Urrusti, J., and Moralies, C.: Selective and directional transfer of $7 \mathrm{~S}$ $\gamma_{2}$-globulin across the human placenta. Nature, Lond. 203: 86-87 (1964).

4 Hyvarinen, M.; Zeltzer, P.; Oh, W., and Stiehm, R.: Influence of gestational age on serum levels of alpha-1 fetoprotein, IgG globulin, and albumin in newborn infants. J. Pediat. 82: 430-437 (1973).
5 Kohler, P.F. and Farr, R. S.: Elevation of cord over maternal IgG immunoglobulin: evidence for an active placental IgG transport. Nature, Lond. 210: 1070-1071 (1966).

6 Maddison, S. E.; Stewart, C. C.; Farshy, C. E., and Reimer, C.B.: The relationship of race, sex, and age to concentrations of serum immunoglobulins expressed in international units in healthy adults in the USA. Bull. Wld Hith Org. 52: 179-186 (1975).

7 Maddison, S. E. and Reimer, C. B.: Normative values of serum immunoglobulins by single radial immunodiffusion: a review. Clin. Chem. 22: 594-601 (1976).

8 Thom, H.; McKay, E., and Gray, D.: Immunoglobulins in umbilical cord plasma. Archs Dis. Childh. 42: 259-263 (1967).

9 Weir, D.M.: Handbook of experimental immunology, vol. 1: Immunochemistry (Blackwell, Oxford 1973).

10 Williams, R.C. and Gershowitz, H.: Gm allotypes in mother-father-cord trios. Vox Sang. (in preparation).

Received: December 28, 1978

Accepted: March 19, 1979

Dr. H. Gershowitz,

Department of Human Genetics, The University of Michigan Medical School, 1137 East Catherine Street, Ann Arbor, MI 48109 (USA) 